\title{
RESEARCH ON CORS (Continuously Operating Reference Station) SYSTEM-BASED REGIONAL WATER VAPOR RETRIEVAL IN GUILIN
}

\author{
Conglin Zhou ${ }^{1}$, Yifei Yang ${ }^{1}$,Maohua Yao $^{1}$,Xinying Zhong ${ }^{1}$,Chaoming Liao ${ }^{2 *}$ \\ ${ }^{1}$ Natural Resources Information Center of Guangxi Zhuang Autonomous Region, Nanning, Guangxi, 530023, China - \\ 572986434@qq.com \\ ${ }^{2}$ School of Natural Resources and Surveying, Nanning Normal University, 530001, Nanning, China - \\ 573014033@qq.com
}

KEY WORDS: Guangxi CORS, PWV(precipitable water vapor), Atmospheric weighted average temperature, Sounding data, GAMIT

\begin{abstract}
:
This paper was aimed at analyzing and verifying each of the parameter settings in the computing process of GAMIT. The optimum number of introduced auxiliary station was determined, and models for the weighted mean temperature of the atmosphere in Guilin were established. Under the underlying strategy of introducing all the respective most optimum criteria, the precipitable water vapor (PWV) was first calculated by using the data provided by the CORS base station in Guilin, before analyzing and comparing it with the PWV and actual precipitation obtained from the sounding data. According to the result, a high degree of coincidence was discovered among the general trend of the following three indicators: the calculated PWV, as well as the PWV and actual precipitation acquired using the sounding data, hence offering a significant value for reference in terms of extreme weather warning.
\end{abstract}

\section{INTRODUCTION}

The climate in the whole Guangxi is greatly affected by the complex airflow on sea level in the southeast, and typhoon will invade from Guangdong every year, thereby bringing heavy rainfall to Guangxi. Guilin is located in the rain-prone north Guangxi, with an average annual rainfall of more than $1500 \mathrm{~mm}$. Xing' an, Yongfu and etc. selected in the experiment are located in the Xing'an-Yongfu-Damiao Mountain rainstorm center in northern Guangxi. The average daily rainfall in rainy season reaches 200-600 $\mathrm{mm}$, which provides the environmental basis for the research experiment. In this paper, the base station observation data of Guangxi CORS network was processed with GAMIT/GLOBK software in combination with IGS station data, sounding meteorological data (Guilin 57957 sounding station) and ground meteorological data ${ }^{[1]}$, with the processing results truly reflecting the rainfall situation in the research area, and then the water vapor retrieval accuracy in the research area was analyzed and verified. By collecting the sounding data of the whole year of 2017 in Guilin, this paper established the model formula applicable to the weighted average atmospheric temperature in Guilin by means of statistical method. PWV was obtained through the inversion of CORS base station data in Guilin in August, 2017, and the time series analysis was conducted with the atmospheric precipitable water vapor (PWV) obtained from the calculation of sounding data, so as to verify the calculation accuracy. In addition, the water vapor generation and extinction trend of the heavy rainfall In guilin on August 21, 2017 solstice 24 was analyzed, so as to discuss the correlation between atmospheric PWV and actual rainfall.

\section{CALCULATION OF GPS WATER VAPOR INVERSION}

\subsection{Experimental area selection}

The experiment target area is Guilin CORS network, including Xing 'an JZ87, Huangsha JZ88, Gongcheng JZ94, Yongfu JZ92 and other stations. The average distance between two stations is $45 \mathrm{~km}$, as shown in Figure.1.

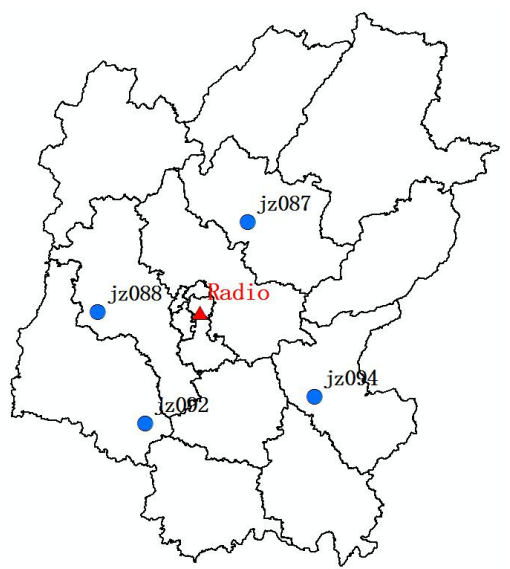

Figure 1. Distribution map of CORS stations and radiosonde stations used in the experiment.

First author: Conglin Zhou - E-mail:572986434@qq.com.

*Corresponding author: Chaoming Liao - E-mail:573014033@qq.com.

Fund projects: Guangxi Natural Science Foundation (2018GXNSFAA138168); science and technology projects of Guangxi surveying and Mapping Bureau (2016-E-01; 2018-E-0); science and technology projects of Guangxi Normal University (0819-2016L11). 


\subsection{Inversion calculation process of PWV}

The process of ground-based GPS inversion of atmospheric PWV can be divided into two parts: measurement and meteorology ${ }^{[2]}$. The whole process is divided into the following four steps: (1) calculate the total tropospheric delay ZTD over the target area by using the data of CORS base station; (2) calculate the statics delay, namely, the dry delay ZHD, by using the pressure, dew point temperature of the target area or the longitude and latitude coordinates of the meteorological observation station ${ }^{[3]}$; (3) calculate the wet-delay ZWD in the troposphere required in the experiment by comparing the difference between ZTD and ZHD; (4) establish the atmospheric weighted average temperature model applicable to the target area, and calculate the water vapor conversion parameters $(\Pi)$, thus getting the corresponding atmospheric $\mathrm{PWV}^{[4]}$.

In the calculation of precipitable water vapor, the conversion of wet delay is closely related to the temperature of troposphere ${ }^{[5]}$. The average temperature of water vapor weight in the troposphere needs to be introduced in the calculation process, namely, the weighted average atmosphere temperature, which is expressed by $\mathrm{Tm}$, with the unit of $\mathrm{K}$.

$$
\begin{gathered}
P W V=\left(k / \rho_{w}\right) \cdot \Delta s=\frac{10^{6}}{\rho_{w} R_{v}\left(k_{2}+k_{3} / T_{m}\right)} \cdot \Delta s=\Pi \cdot \Delta s(1) \\
\Pi=\frac{10^{6}}{\rho_{w} R_{v}\left(k_{2}^{\prime}+k_{3} / T_{m}\right)} \\
P W V=\Pi \cdot Z W D
\end{gathered}
$$

In the formula above, $\rho$ is the density of liquid water; $\Pi$ can be regarded as a dimensionless constant, namely, the conversion coefficient between ZWD and PWV, which represents the conversion ratio between wet delay and precipitable water. The dimensionless constant is 0.15 according to experience. That is to say, $1 \mathrm{~mm}$ PWV will cause a signal delay of 6.4 or $6.5 \mathrm{~mm}{ }^{[6]}$. Formula (1) shows a linear relationship between the two, which can be simplified as Formula (3).

\section{SELECTION AND VERIFICATION OF EXPERIMENTAL CONDITIONS}

\subsection{Determination of the optimal number of auxiliary} stations outside the network

When GAMIT software is used to calculate PWV in the observation data of CORS station, the results obtained are the relative PWV between observation stations; in order to reduce the correlation between the calculation results of different observation stations, and obtain absolute PWV of each station, it is required to add a long base line more than $500 \mathrm{~km}$ in the regional CORS network, so as to improve the calculating accuracy, and reduce its correlation ${ }^{[3]}$. It is necessary to control the calculation workload of experimental data in a reasonable range while improving the calculation accuracy. Therefore, the data of the following international IGS observation stations was introduced in this experiment, including Beijing Fangshan (BJFS), Lhasa (LHAZ), Taiwan Taoyuan (TWTF), Bangkok (CUSV), Changchun (CHUN) and Urumqi (URUM). In the experimental operation, the following seven solutions were employed:

Table 1 Addition of test scheme of auxiliary stations outside the network

\begin{tabular}{ccc}
\hline $\begin{array}{c}\text { Sche } \\
\text { me }\end{array}$ & $\begin{array}{c}\text { Addition of GPS observation } \\
\text { stations }\end{array}$ & $\begin{array}{c}\text { Number of } \\
\text { observation } \\
\text { stations } \\
\text { introduced }\end{array}$ \\
\hline 1 & NONE & 0 \\
2 & TWTF & 1 \\
3 & BJFS TWTF & 2 \\
4 & BJFS LHAZ TWTF & 3 \\
5 & BJFS LHAZ TWTF CUSV & 4 \\
6 & BJFS LHAZ TWTF CUSV CHUN & 5 \\
7 & BJFS LHAZ TWTF CUSV CHUN & 6 \\
\hline
\end{tabular}

The observation data from the stations in the four days (47-50th DOY day of 2017) was selected in the experiment. After the completion of data arrangement, according to the seven schemes in Table 1, GAMIT software was used to calculate the total tropospheric delay of each observation station in combination with the data of CORS base station.

\begin{tabular}{|c|c|c|c|c|c|c|c|}
\hline Station & Type & D60 & D61 & D62 & D63 & D64 & D65 \\
\hline \multirow{3}{*}{ Xing 'an } & MEAN & 32.71 & 5.37 & -4.33 & -0.59 & -0.07 & -0.56 \\
\hline & RMS & 36.23 & 8.61 & 5.76 & 2.58 & 2.03 & 1.31 \\
\hline & $\mathrm{R}$ & 0.412 & 0.904 & 0.973 & 0.987 & 0.992 & 0.997 \\
\hline \multirow{3}{*}{ Huangsha } & MEAN & 33.73 & 6.31 & -4.27 & -0.41 & 0.32 & 0.05 \\
\hline & RMS & 37.65 & 9.39 & 5.78 & 2.66 & 2.16 & 1.19 \\
\hline & $\mathrm{R}$ & 0.341 & 0.891 & 0.972 & 0.985 & 0.991 & 0.997 \\
\hline \multirow{3}{*}{ Yongfu } & MEAN & 32.33 & 5.18 & -4.7 & -0.88 & -0.21 & -0.59 \\
\hline & RMS & 36.46 & 8.76 & 6.15 & 2.72 & 2.15 & 1.37 \\
\hline & $\mathrm{R}$ & 0.561 & 0.927 & 0.979 & 0.991 & 0.994 & 0.998 \\
\hline \multirow{3}{*}{ Gongcheng } & MEAN & 33.28 & 5.45 & -4.48 & -0.86 & -0.04 & -0.73 \\
\hline & RMS & 37.06 & 9.01 & 6.12 & 3.12 & 2.04 & 1.65 \\
\hline & $\mathrm{R}$ & 0.575 & 0.925 & 0.973 & 0.987 & 0.993 & 0.997 \\
\hline
\end{tabular}

Table 2 Determination of the optimal number of auxiliary stations outside the CORS network in Guilin

Note: D60,D61,D62,D63,D64 and D65 respectively represent the differences between the calculated tropospheric delay with different number of auxiliary stations and that with six auxiliary stations. 
As can be seen from Table 2, the calculation results were significantly improved after the addition of a long-distance auxiliary station. The mean value of the four stations decreased from about $33 \mathrm{~mm}$ to about $6 \mathrm{~mm}$, and the root mean square basically decreased by $28 \mathrm{~mm}$. The mean value and root mean square of the difference between the tropospheric delay when 4 auxiliary stations were introduced and that when 6 auxiliary stations were introduced in the target observation station were $0.14 \mathrm{~mm}$ and $2.2 \mathrm{~mm}$ respectively, and the accuracy of converted PWV was close to $1 \mathrm{~mm}$, with the correlation up to $99 \%$. At this time, the calculation results could meet the requirements of meteorological application.

\subsection{Localization of atmospheric weighted average}

\section{temperature model}

The accuracy of atmospheric weighted average temperature model $T_{m}$ is related to the accuracy of water vapor conversion factor, which will directly affect the accuracy of final calculation results. In this paper, the localized method of Bevis empirical formula ${ }^{[7]}$ (see Formula 6) was employed to establish the weighted average atmospheric temperature model applicable to Guilin area. $T_{m}$ is the regional weighted average atmospheric temperature, namely,the dependent variable, $T_{s}$ is the ground temperature, that is, the independent variable. The quarterly adaptive regression model (see Formula 7) and the 2017 annual regression model (see Formula 8) are established through the linear regression analysis theory ${ }^{[8][9]}$.

Bevis empirical formula ${ }^{[10]}$ :

$$
T_{m}=0.720 T_{s}+70.20
$$

The regression model established from the data of 7,8 and 9 months is as follows:

$$
T_{m}=0.643 T_{s}+94.25
$$

The regression model established based on the data of the whole year of 2017 is as follows:

$$
T_{m}=0.631 T_{s}+97.51
$$

In order to analyze the applicability of each model, the surface temperature of radiosonde data from January to March in Guilin area were substituted into Formula (6) $\sim$ (8) based on the true value of the weighted average atmospheric temperature in radiosonde data, so as to calculate their weighted average atmospheric temperatures, which were compared with true values for drawing the residual plot of each model, and making precision analysis.

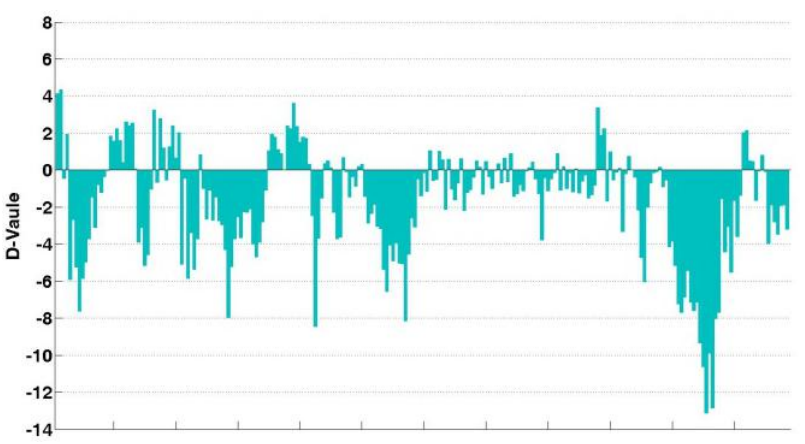

Figure 2. Bevis empirical formula model residual errors

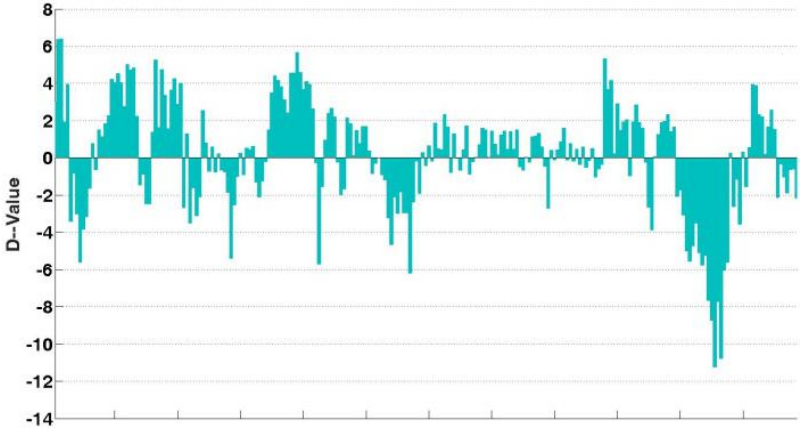

Figure 3. Formula model residual errors based on sounding data in q3 2017

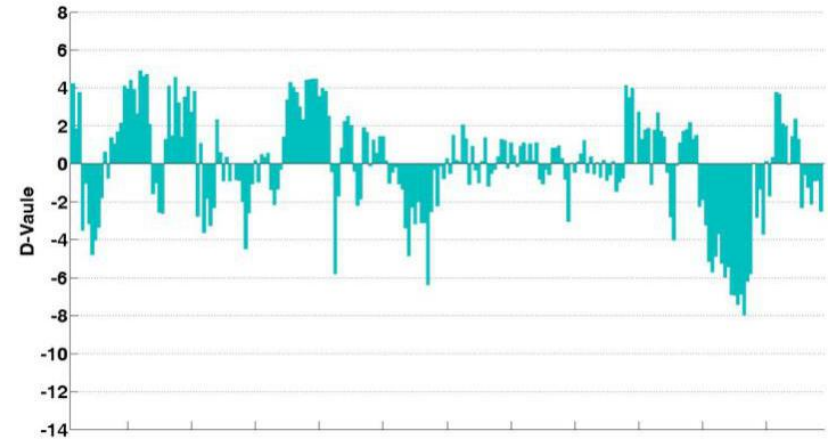

Figure 4. Formula model residual errors based on the sounding data in the whole year of 2017

Through the comparative analysis of Figure. 2 and Figure. 4, the residual errors of Bevis empirical formula model are generally distributed between -14 and 4 , and the residual values of the other two models are mostly distributed between -12 and 6 . It could be known that the residual errors of Bevis empirical formula are larger than those of the two models based on the sounding data of Guilin area. In order to make a more intuitive comparison, the mean value, mean square root and correlation coefficient of the three are calculated as follows:

Table 3 Accuracy comparison of three empirical formulas

\begin{tabular}{cccc}
\hline $\begin{array}{c}\text { Statistical } \\
\text { type }\end{array}$ & $\begin{array}{c}\text { Bevis } \\
\text { empirical } \\
\text { formula }\end{array}$ & $\begin{array}{c}\text { Empirical } \\
\text { formula for } \\
\text { 12 months } \\
\text { sounding data }\end{array}$ & $\begin{array}{c}\text { Empirical } \\
\text { formula for } \\
\text { 3-month } \\
\text { sounding data }\end{array}$ \\
\hline $\begin{array}{c}\text { MEAN } \\
\text { RMS } \\
\text { (root-me }\end{array}$ & 2.44 & 2.16 & 2.18 \\
$\begin{array}{c}\text { an-square } \\
\text { value })\end{array}$ & 3.41 & 2.9 & 2.91 \\
$\begin{array}{c}\text { R(correlati } \\
\text { oncoeffici } \\
\text { ent) }\end{array}$ & 0.857 & 0.895 & 0.886 \\
\hline
\end{tabular}

It can be seen from Table 3 that, based on the comprehensive indexes, the mean value, mean error and root mean square error of the model empirical formula established based on 12 months 'sounding data are less than those of the other two formulas, and the correlation coefficient is better than the expectation model formula established by 3 months' sounding data. To sum up, the model formula in this experiment is the atmospheric weighted average temperature formula established based on the sounding data of Guilin area in 2017. 


\section{CASE ANALYSIS}

\subsection{Correlation analysis between CORS/PWV and} Radio/PWV

The sounding data selected in this paper is the observation data of No. 57957 meteorological sounding station in Guilin to calculate PWV, and CORS inversion PWV is selected from August 2017.
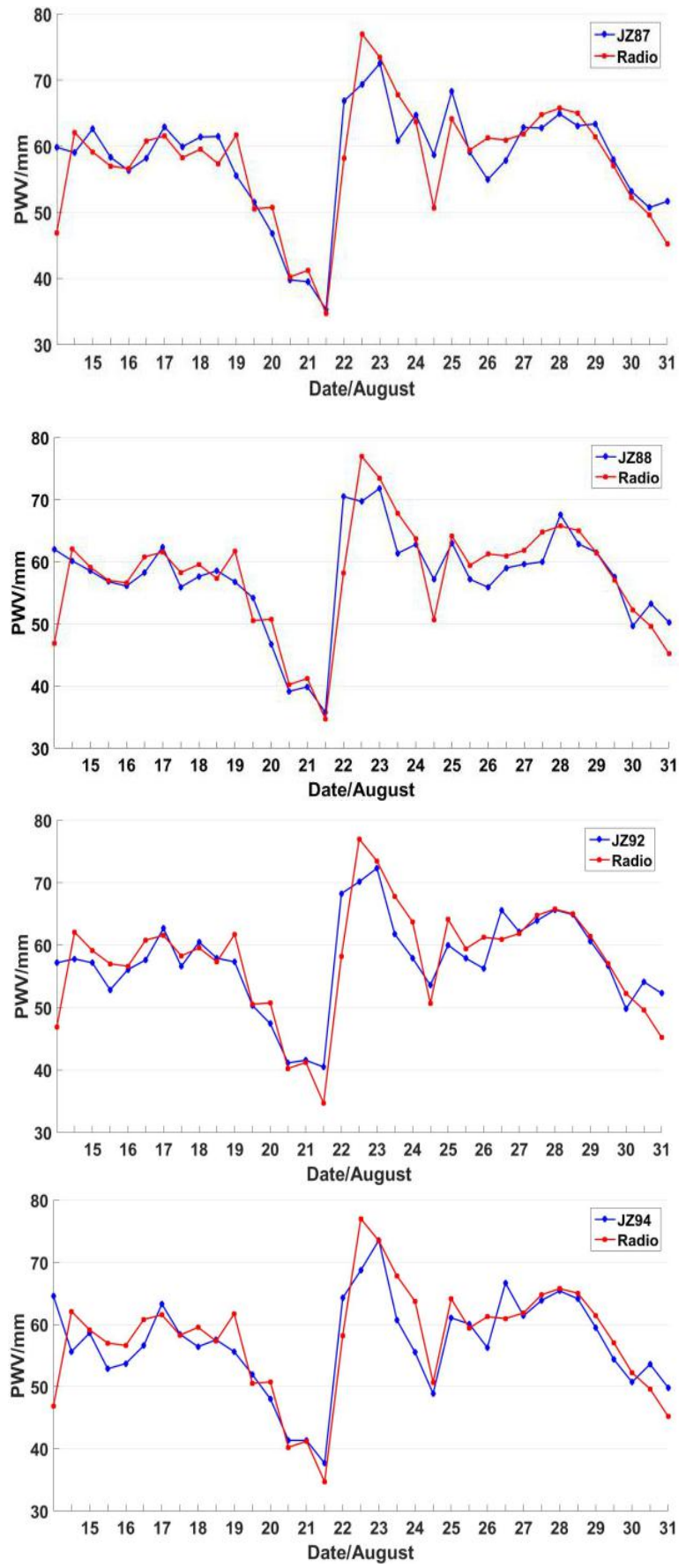

Figure 5. Sequence diagram of Radio/PWV and CORS/PWV

As can be seen from the figure, the trend of CORS/PWV data of several benchmark stations in Guilin area is basically the same.It is very consistent with the trend of Radio/PWV. PWV value fluctuates sharply mainly from the $21 \mathrm{st}$ to the $24 \mathrm{th}$. Based on the meteorological data of the same period in Guilin, it is found that the No. 13 Typhoon Hato passed through Guangxi in 2017 during this period, bringing a large-scale heavy rainfall to Guilin area.

Table 4 Analysis and statistics of difference between CORS / PWV and radio / PWV

\begin{tabular}{ccccccc}
\hline Station & $\begin{array}{c}\text { MEAN/ } \\
\mathrm{mm}\end{array}$ & $\begin{array}{c}\mathrm{mAX} / \\
\mathrm{mm}\end{array}$ & $\begin{array}{c}\mathrm{MIN} / \\
\mathrm{mm}\end{array}$ & $\begin{array}{c}\text { STD } \\
\text { /mm }\end{array}$ & $\begin{array}{c}\text { RMS } \\
\text { /mm }\end{array}$ & R \\
\hline $\mathrm{JZ87}$ & -0.273 & 7.620 & -12.980 & 4.415 & 4.426 & 0.867 \\
$\mathrm{JZ88}$ & 0.309 & 7.290 & -15.170 & 4.821 & 4.829 & 0.839 \\
$\mathrm{JZ92}$ & 0.519 & 8.060 & -13.050 & 4.059 & 4.092 & 0.888 \\
$\mathrm{JZ94}$ & 0.659 & 8.290 & -17.730 & 5.146 & 5.188 & 0.815 \\
\hline
\end{tabular}

It can be seen from the chart analysis, The base station data of CORS/PWV has good consistency with that of Radio/PWV in both overall variation trend and peak point. Moreover, the error before and after the time when the value of CORS/PWV reaches the peak value is less than one hour, which has strong timeliness.

Nevertheless, it was found that CORS/PWV was larger than Radio/PWV on the whole in the statistics of differences, which was most obvious in Gongcheng JZ94, with the maximum difference up to $17.73 \mathrm{~mm}$ and the mean value up to $0.659 \mathrm{~mm}$. The mean difference of Xing 'an JZ87 station is the smallest, with a difference value of $0.27 \mathrm{~mm}$. This was caused by many factors, such as the end effect in the data, the difference of self-adaptive regional weighted average temperature model, and the different altitudes of radiosonde stations and CORS stations.

Generally, the mean error of CORS/PWV and Radio/PWV is about $0.4 \mathrm{~mm}$, and the RMS error is 4.4 $\mathrm{mm}$. The overall correlation reached 0.85.It is proved that the PWV calculated by GPS has a good reference property and can reflect the change characteristics of water vapor.

\subsection{Comparison between the PWV calculated based} on GPS data and the actual precipitation

The paper analyzes the CORS data of Huangsha, Yongfu, Xing 'an and Gongcheng stations based on the actual precipitation sequence of the study area, as shown in the figure.

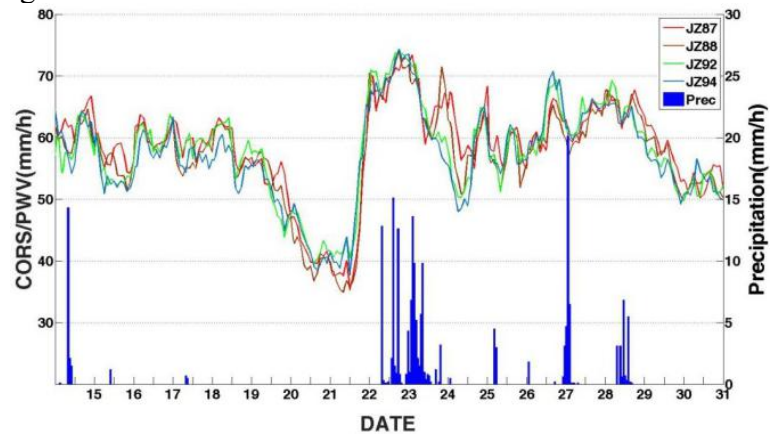

Figure 6. PWV sequence and actual precipitation diagram 
As can be seen from the figure, the change trend of CORS/PWV of the four sites was basically the same, especially during the heavy rainfall from the 21 st to the 23rd, which maintained a high degree of consistency.It shows that there is a significant correlation between the PWV and the actual precipitation.Under the strong influence of typhoon No.13 in 2017 , the PWV value in Guilin area bottomed out from 12:00 on the 21 st, then increased sharply, the short-term change rate reached more than $10 \mathrm{~mm} / \mathrm{h}$, returned to the peak within 4 hours, and kept until the early morning of the 24th, then gradually decreased, and showed the short-term peak changes in the early morning of the 25 th, 20:00 on 26th and the morning of the 28th, respectively. At the same time, from 13:00 on the $22 \mathrm{nd}$, the continuous rainfall in Guilin reached more than $30 \mathrm{~mm} / \mathrm{d}$ and lasted until $4: 00$ am on the 24 th. Then, a low-intensity rainfall occurred at 8:00 am on the $25 \mathrm{th}$, and another heavy rainfall occurred at $21: 00 \mathrm{pm}$ on the $26 \mathrm{th}$. The rainfall exceeded $50 \mathrm{~mm} /$ $\mathrm{h}$, reaching the rainstorm level, and ended at 1:00 am on the 27th.Another rainfall occurred,around the early morning of the 28th.Most of the precipitation has occurred near the peak or trough of the PWV from the 21 st.There is a good agreement between the PWV change rate and precipitation.It can be said that the greater the PWV change rate, the greater the precipitation in general.

However, there are many factors that affect rainfall, and the formation of weak precipitation is relatively random and has poor correlation with water vapor.The heavy rainfall is mainly concentrated on the peak or valley value of CORS / PWV.When the CORS / PWV value changes rapidly and the short-term change rate exceeds $20 \mathrm{~mm} \mathrm{/} \mathrm{h,} \mathrm{the} \mathrm{probability} \mathrm{of} \mathrm{rainstorm} \mathrm{increases}$ rapidly.This is because the PWV value is not directly proportional to the actual precipitation.The CORS measures the total atmospheric water vapor amount, which is not sensitive to the liquid water in the cloud.The water vapor gradient, water vapor convergence and divergence, and weather system also have an important impact on the size and duration of precipitation ${ }^{[11]}$.It is necessary to comprehensively consider the conditions such as the conditions of average level, peak value and increase ${ }^{[12]}$.So, strictly speaking,the change rate of CORS / PWV and the sudden change of its peak value can reflect the actual precipitation trend better and play a certain role in precipitation prediction.

\section{CONCLUSION}

The research results of this paper are summarized as follows:

(1) The experiment results showed that the localized atmospheric weighted average temperature model established on the basis of the empirical model showed a good applicability in Guilin, with a correlation of 0.9 , and a root mean square error of only 2.9.

(2) Through experiments, it could be proved that the introduction of four off-network auxiliary stations is the best choice for the tropospheric delay of CORS data calculation.

(3) The experimental results showed that the overall trend of PWV, which was inversely calculated from CORS data, was consistent with the actual rainfall. When the PWV rapidly increased to a high level,that is, when the short-term change rate exceeds $20 \mathrm{~mm} / \mathrm{h}$, it indicated that there was a relatively large amount of water vapor in the atmosphere, and the probability of rainstorm increased rapidly. The high atmospheric water vapor content could provide necessary conditions for rainfall [10]. This time response showed that the PWV calculated based on GPS data had a good short-time forecast for actual rainfall. According to this characteristic, the PWV calculated based on GPS data could be applied to extreme weather monitoring.

\section{REFERENCE}

[1] Li G. P., 2007: Ground based GPS remote sensing of Atmospheric Precipitable Water and its application in meteorology. Chengdu: Southwest Jiaotong University.

[2] Liu Y. P., Wang Y. L., Zhang F. L., 2012: Preliminary application of GPS inversion in Beijing. Journal of Hebei University of technology., 41. 2:74-77.

[3] Wang Y., 2012: Research on the principle and application of ground-based GPS meteorology. Beijing: Mapping Press, 2-7.

[4] Wen H. Y., He M. L., Pan Y. J., Kang J.M., 2012: Application of regional delay model in retrieving water vapor at CORS station. Journal of Surveying and Mapping Science and technology., 29 (06): 406-409.

[5] Yao Y. B., Zhang S., Kong J.2017: Research Progress and Prospect of GNSS Space Environment Science. Acta Gerodaetica et Cartographica Sinica. 46(10):1408-1420

[6] Rocken C., Ware R., VanHove T., Solheim F., Alber C., Johnson J., Bevis M., 1993: Sensing atmospheric water vapour with the Global Positioning System.Geophys.res.lett., 14:2631-2634.

[7] Bevis M.,Businger S.,Herring T-A.,et a1.,1992: GPS meteorology:Remote sensing of atmos pheric water vapor using the global positioning system. Journal of Geophysics Research., 97:15787-15801.

[8] Xie S. F., Jin L.Y., Wang X. Q., Huang L. K., 2017: Weighted average temperature model of atmosphere in Guangxi. Science and technology and engineering., 17 (12): 133-137.

[9] Si H. Y., 2011., Retrieval of Regional Atmospheric Precipitable Water Using CORS data. Chang'an University.

[10] Li G P., Huang D.F., 2006: Progress and Prospect of GPS meteorology research and application. Meteorological science.,25 (6): 651-661.

[11] Liu Z. M., Dou S. B., et al. 2017: Comparative Analysis of Precipitable Water Vapor Acquired from CORS and Radiosonde in Qingdao. Journal Shandong University of Science and Technology., 36(01):21-28.

[12] SOLHEIM F. S., VIVEKANANDAN J., WARE R. H., 1999: Propagation delays induced in GPS signals by dry air,water vapor,hydrometeors, and other 
The International Archives of the Photogrammetry, Remote Sensing and Spatial Information Sciences, Volume XLII-3/W10, 2020 International Conference on Geomatics in the Big Data Era (ICGBD), 15-17 November 2019, Guilin, Guangxi, China

particulates.Journal of Geophysical Research., 104(104):9663-9670 